\title{
CHEMOSPHERE
}

\section{Using stochastic risk assessment in setting information priorities for managing dioxin impact from a municipal waste incinerator}

\author{
Hwong-wen $\mathrm{Ma}^{*}$ \\ Graduate Institute of Environmental Engineering, National Taiwan University, 71 Chou-Shan Road, Taipei 106, Taiwan
}

Received 14 September 2001; received in revised form 28 March 2002; accepted 28 March 2002

\begin{abstract}
The objectives of this study were to assess site-specific carcinogenic risk of incinerator-emitted dioxins in a manner reflecting pollutant transfer across multimedia and multi-pathways. The study used site-specific environmental and exposure information and combined the Monte Carlo method with multimedia modeling to produce probability distributions of risk estimates. The risk estimates were further categorized by contaminated environmental media and exposure pathways that are experienced by human receptors in order to pinpoint significant sources of risk. Rank correlation coefficients were also calculated along with the Monte Carlo sampling to identify key factors that influenced estimation of risk. The results showed that ingestion accounted for more than $90 \%$ of the total risk and that risk control on ingestion of eggs, aboveground vegetables, and poultry should receive priority. It was also found that variation of parameters with variability accounted for around $35 \%$ of the total risk variance, while uncertainty contributed to the remaining $65 \%$. Intake rates of aboveground vegetables, eggs, and poultry were the key parameters with the largest contribution to variance. In addition, sufficient sampling and analysis of dioxin contents in eggs, aboveground vegetables, poultry, soil, and fruit should be performed to improve risk estimation because the variation in concentrations in these media accounted for the largest overall risk variance. Finally, focus should be placed on reduction of uncertainty associated with the risk estimation through ingestion of aboveground vegetables, eggs, poultry, fruit, and soil because the risk estimates associated with these exposure pathways had the largest variance.
\end{abstract}

(C) 2002 Published by Elsevier Science Ltd.

Keywords: PCDD; PCDF; Uncertainty; Sensitivity; Monte Carlo method; Multi-pathway exposure

\section{Introduction}

The health risk associated with incineration of municipal wastes needs to be evaluated in order to protect public health, especially in regions with a high density of incinerators. In Taiwan, it is estimated that the total annual capacity of municipal waste incinerators will be greater than 10 million metric tons by year 2004, accommodating around $94 \%$ of total municipal wastes.

\footnotetext{
${ }^{*}$ Tel.: +886-2-23630406; fax: +886-2-23928830.

E-mail address: hwma@ccms.ntu.edu.tw (H.-w. Ma).
}

However, incineration releases toxic substances, including products of incomplete combustion and metals (Siebert and Alston, 1991; Dempsey and Oppelt, 1993). Of the pollutants emitted, polychlorinated dibenzo$p$-dioxins (PCDDs) and polychlorinated dibenzofurans (PCDFs) raise the most concern due to associated health effects such as immune, nervous, endocrine, reproductive, and carcinogenic potential (WHO, 1999). In fact, waste incineration has been recognized to be the predominant source of dioxin release, accounting for $60 \%$ to more than $90 \%$ of total release in various countries (Alcock et al., 1999; Gotoh and Nakamura, 1999; Lauretis, 1999). 
Recently, site-specific risk assessment is increasingly being used as a tool for quantifying health consequences resulting from contact with risk agents (e.g., chemical contaminants) and as a basis for developing risk management measures (NRC, 1994; Crawford-Brown, 1999; USEPA, 1999). On one hand, site-specific risk assessment produces more accurate estimation than traditional generic risk assessment because it considers realistic source characteristics, land use patterns, environmental conditions, and residents' lifestyles to establish site-specific exposure. On the other hand, the increased complexity boosts demand for information. The accuracy of risk estimation is limited by the availability and correctness of information, so it is essential to identify key parameters among the large information requirements. Among the various environmental media (i.e., air, soil, water body) and exposure media (the media that human receptors contact directly, such as drinking water and foods) that need to be modeled in order to produce risk estimates, it is also crucial to identify their relative importance in assessing risk so that sampling and analysis can then be performed more efficiently by focusing on important media. In addition, the significant sources of risk in terms of combination of exposure pathways and environmental media need to be identified to facilitate development of risk management measures. Pollutants move from incinerator emissions to environmental media and then to exposure media, so efficient risk management measures can be searched for along the chain of movement when important pathways that connect environmental media with exposure media are identified. In the past, the previous issues associated with waste incineration were rarely addressed (Levin et al., 1991; Valberg et al., 1996).

This research used site-specific environmental and exposure information to conduct stochastic multimedia risk assessment for dioxin emissions from a municipal waste incinerator. The purpose was threefold: first, to identify key parameters that had a major influence on risk estimation; second, to identify important environmental media and exposure media that significantly affected estimation of risk; lastly, to identify environmental media and exposure pathways that served as the primary sources of risk.

\section{Methodology}

\subsection{Incinerator and emission characterization}

Shulin incinerator, which is located in northern Taiwan, was chosen as the studied case because it is the biggest municipal waste incinerator that has operated for more than 2 years and had the most complete dioxin emission data. The average emission rates of the 17 di-
Table 1

Basic characteristics and emission rates of 17 dioxin congeners for Shulin municipal waste incinerators

\begin{tabular}{|c|c|}
\hline Capacity (tons d ${ }^{-1}$ ) & 1350 \\
\hline Stack height (m) & 117 \\
\hline Stack diameter (m) & 2.0 \\
\hline Exit flow (dscm $\left.\min ^{-1}\right)$ & 1958 \\
\hline Exit temperature $\left({ }^{\circ} \mathrm{C}\right)$ & 147 \\
\hline Furnace type & Reverse-acting \\
\hline Air pollution control device & $\begin{array}{l}\text { Cyclone }+ \text { dry scrubber } \\
\text { with activated carbon } \\
\text { injection }+ \text { bag filter }\end{array}$ \\
\hline $2,3,7,8,-\mathrm{TeCDF}\left(\mathrm{g} \mathrm{s}^{-1}\right)$ & $1.86 \mathrm{E}-07$ \\
\hline $1,2,3,7,8,-\mathrm{PeCDF}\left(\mathrm{g} \mathrm{s}^{-1}\right)$ & $9.91 \mathrm{E}-08$ \\
\hline $2,3,4,7,8,-\mathrm{PeCDF}\left(\mathrm{g} \mathrm{s}^{-1}\right)$ & $9.94 \mathrm{E}-08$ \\
\hline $1,2,3,4,7,8-\mathrm{HxCDF}\left(\mathrm{g} \mathrm{s}^{-1}\right)$ & $1.44 \mathrm{E}-07$ \\
\hline $1,2,3,6,7,8-\mathrm{HxCDF}\left(\mathrm{g} \mathrm{s}^{-1}\right)$ & $8.22 \mathrm{E}-08$ \\
\hline $2,3,4,6,7,8-\mathrm{HxCDF}\left(\mathrm{g} \mathrm{s}^{-1}\right)$ & $8.54 \mathrm{E}-08$ \\
\hline $1,2,3,7,8,9-\mathrm{HxCDF}\left(\mathrm{g} \mathrm{s}^{-1}\right)$ & $1.28 \mathrm{E}-08$ \\
\hline $1,2,3,4,6,7,8-\mathrm{HpCDF}\left(\mathrm{g} \mathrm{s}^{-1}\right)$ & $1.92 \mathrm{E}-07$ \\
\hline $1,2,3,4,7,8,9-\mathrm{HpCDF}\left(\mathrm{g} \mathrm{s}^{-1}\right)$ & $3.48 \mathrm{E}-08$ \\
\hline OCDFC $\left(\mathrm{g} \mathrm{s}^{-1}\right)$ & $1.47 \mathrm{E}-07$ \\
\hline $2,3,7,8-\mathrm{TeCDD}\left(\mathrm{g} \mathrm{s}^{-1}\right)$ & $6.60 \mathrm{E}-09$ \\
\hline $1,2,3,7,8-\mathrm{PeCDD}\left(\mathrm{g} \mathrm{s}^{-1}\right)$ & $1.68 \mathrm{E}-08$ \\
\hline $1,2,3,4,7,8-\mathrm{HxCDD}\left(\mathrm{g} \mathrm{s}^{-1}\right)$ & $9.76 \mathrm{E}-09$ \\
\hline $1,2,3,6,7,8-\mathrm{HxCDD}\left(\mathrm{g} \mathrm{s}^{-1}\right)$ & $1.31 \mathrm{E}-08$ \\
\hline $1,2,3,7,8,9-\mathrm{HxCDD}\left(\mathrm{gs}^{-1}\right)$ & $1.91 \mathrm{E}-08$ \\
\hline $1,2,3,4,6,7,8-\mathrm{HpCDD}\left(\mathrm{g} \mathrm{s}^{-1}\right)$ & $7.57 \mathrm{E}-08$ \\
\hline OCDD $\left(\mathrm{g} \mathrm{s}^{-1}\right)$ & $1.54 \mathrm{E}-07$ \\
\hline TEQ $\left(\mathrm{g} \mathrm{s}^{-1}\right)$ & $1.36 \mathrm{E}-07$ \\
\hline
\end{tabular}

oxin congeners in addition to the basic incinerator characteristics are shown in Table 1 . The average emission rate in terms of $\mathrm{g}$-TEQ $\mathrm{s}^{-1}$ was $1.36 \mathrm{E}-7$ with a concentration of $5.743 \mathrm{ng}$-TEQ Nm${ }^{-3}$. The incinerator began operation in year 1995 with a capacity of 1350 tons $\mathrm{d}^{-1}$. A cyclone, a dry scrubber with injection of activated carbon, and a bag filter were used to control air emissions.

\subsection{Multimedia risk assessment}

A multimedia risk model that combined multimedia exposure and exposure-response relationships was used to predict health risk of human receptors. Multimedia exposure modeling involved predicting the transport of dioxin emissions within the air and the transfer across environmental media and estimating the dosages human receptors received through multiple pathways (Covello and Merkhofer, 1993). In this study, the multimedia exposure model was constructed by linking singlemedium models so the outputs of one model were used as the inputs of the next. The single-medium models were based on uniformly mixed compartments and the 
transfer between compartments followed first-order processes (McKone, 1991), except that spatial heterogeneity of concentrations in the air compartment was calculated through air dispersion modeling. The algorithms for soil and water transport and food chain transfer used in California EPA (1993), the Multimedia Environmental Pollutant Assessment System (Strenge and Chamberlain, 1995), and USEPA (1999) were combined to estimate multimedia and multi-pathway exposure to dioxins.

The procedures of performing multimedia risk assessment included the following seven steps. First, the study area (within $5 \mathrm{~km}$ of the incinerator) was divided into sectors by a Cartesian grid, which consisted of 1600 sectors, each of which with dimension of $250 \mathrm{~m} \times 250$ $\mathrm{m}$. Second, the industrial source complex short-term model (ISCST3) was used to estimate each dioxin congener's ambient concentration and deposition in every sector within the study area (USEPA, 1995). Dioxin's dispersion in vapor and particle phases was modeled separately and the vapor-particle partition was incorporated to obtain average air concentrations and depositions in each sector. Third, ISCST-modeled air deposition rates were used to calculate the concentrations of each congener in the soil of each sector and watersheds; the concentrations in the water bodies that served as the sources of drinking water and fish were then calculated based on air deposition and diffusion, surface runoff, and erosion from the associated watersheds. Fourth, the estimated concentrations in the environmental media (air, soil, and water) were used with food chain modeling to predict food concentrations as a result of exposure to the polluted environmental media. These included predicting concentrations of each congener in aboveground produce, fruits, beef, dairy, and pork in each sector as a result of air contamination, predicting concentrations in root vegetables, beef, dairy, pork, chicken, and eggs as a result of soil contamination, and predicting concentrations in drinking water and fish as a result of contaminated water bodies. Fifth, the griddivided sectors were overlaid with the smallest administrative units (SAU) by using a geographic information system to determine each congener's concentrations in the environmental media and in the foods of each SAU as a result of contamination in each environmental medium. Sixth, the contact rates between human receptors and exposure media (air, drinking water, and foods) were used to determine residents' dioxin exposure through individual exposure pathways in each SAU around the incinerator. Twelve exposure pathways were considered, including inhalation, and ingestion of soil, drinking water and nine food items. The following equation calculated the average daily intake of dioxins, $\mathrm{ADI}_{j k}\left(\mathrm{mg}-\mathrm{TEQ} \mathrm{kg} \mathrm{kg}^{-1} \mathrm{~d}^{-1}\right.$, from environmental medium $j$ and exposure medium $k$.
$\mathrm{ADI}_{j k}=\sum_{i} C_{i j k} \times \mathrm{TEF}_{i} \times \frac{\mathrm{IU}_{k}}{\mathrm{BW}} \times \frac{\mathrm{EF} \times \mathrm{ED}}{\mathrm{AT}}$

where $C_{i j k}$ is the concentration of congener $i$ in exposure medium $k$ as a result of contaminated environmental medium $j . \mathrm{TEF}_{i}$ is the international toxicity equivalency factor of congener $i$ based on its relative toxicity to 2,3,7,8-TCDD. $\mathrm{IU}_{k}$ is the contact rate of exposure medium $k$. EF is the exposure frequency, ED is the exposure duration, and AT is the averaging time. BW is the body weights of receptors. Lastly, the average daily intake was multiplied by a cancer slope factor of $1.56 \times 10^{5}\left(\mathrm{mg}\right.$-TEQ $\left.\mathrm{kg}^{-1} \mathrm{~d}^{-1}\right)$ to obtain the caner risk estimate (USEPA, 1992).

\subsection{Uncertainty analysis}

The Monte Carlo method along with the multimedia risk assessment described above (excluding air dispersion modeling) was used to combine individual probability distributions of model parameters to produce a probability distribution of risk estimation for the residents living in the SAU with the largest air deposition (USEPA, 1997; Ma, 2000). The ISC-modeled concentrations and deposition rates of all congeners in those sectors within the SAU were used to derive probability distributions of air concentrations and deposition rates. In addition to the 17 congeners' air concentrations and deposition rates, there were 88 parameters related to properties of environmental media, 19 parameters related to exposure characteristics, and 427 parameters related to the 17 congeners' physico-chemical properties. The distributions used in California EPA (1993), Strenge and Chamberlain (1995), and USEPA (1999) were drawn onto complement site investigation to estimate the probability density function (pdf) associated with individual parameters. For each of the parameters, one value was selected at random with respect to the associated pdf. The individual cancer risk was then calculated with the sampled set of input values. The sampling and calculation were repeated 2000 times to produce the pdf of the risk estimate through individual transport and exposure pathways.

Rank correlation coefficients between input parameters and risk outputs were calculated and the correlation coefficients for all the parameters were squared and normalized to calculate their contribution to the total variance (Iman and Helton, 1988; Mills et al., 1999). The types of uncertainties (uncertainty or variability) for each parameter were identified and the relative contribution of the two types of uncertainties was calculated. Uncertainty, which is due to lack of knowledge of the true values, can be reduced through further research or sampling, while variability, which is due to spatiotemporal heterogeneity, cannot be reduced. This study 
treated chemical-specific parameters (for example, the bioconcentration factors) and the environmental parameters (for example, density of air) within the study area (with the exception of precipitation, wind speed, and ambient temperature) as uncertain, while treating the three parameters in parentheses as temporally variable and the exposure parameters (for example, consumption rate of beef) as variable across the study population (i.e., inter-subject variability). In total, there were 512 parameters with uncertainty and 22 parameters with variability. The study also identified the relative importance of specific environmental media and exposure media as well as of exposure pathways in terms of their influence on risk estimates by calculating the rank correlation coefficients (and then contribution to variance) between dioxin concentrations for these media and total risk outputs, and between risks of individual pathways and total risk outputs among the 2000 sets of Monte Carlo-simulated samples.

\section{Results and discussion}

Table 2 presents the contribution to overall variance of cancer risk estimates for the 15 parameters that had contribution no less than $1 \%$. The variation of the 15 parameters accounted for around $54 \%$ of the overall risk variance. When uncertainty was distinguished from variability, uncertainty accounted for about $65 \%$ of the total variance while variability accounted for the remaining $35 \%$, meaning that if all the parameters could be estimated accurately, around $65 \%$ of the variance associated with the risk estimation would be eliminated. Among the parameters with variability, intake rates of aboveground vegetables, eggs, poultry, and fruit, and body weight, in descending order of importance, had major impact on risk estimation. The parameter with the largest contribution, around $13 \%$, was intake rate of
Table 2

Contribution of important parameters to the variance of the total risk estimate

\begin{tabular}{|c|c|}
\hline Parameter & $\begin{array}{l}\text { Variance } \\
\text { contribu- } \\
\text { tion }(\%)\end{array}$ \\
\hline All parameters with variability & 35 \\
\hline Intake rate of aboveground vegetables ${ }^{\mathrm{a}}$ & 13 \\
\hline Intake rate of $\operatorname{eggs}^{\mathrm{a}}$ & 10 \\
\hline Intake rate of poultry ${ }^{\mathrm{a}}$ & 6 \\
\hline Intake rate of fruit ${ }^{\mathrm{a}}$ & 2 \\
\hline Body weight ${ }^{\mathrm{a}}$ & 2 \\
\hline All parameters with uncertainty & 65 \\
\hline Fraction of chicken diet that is soil ${ }^{\mathrm{b}}$ & 4 \\
\hline USLE cover management factor ${ }^{\mathrm{b}}$ & 3 \\
\hline USLE length-slope factor ${ }^{\mathrm{b}}$ & 3 \\
\hline Interception fraction of aboveground vegetables ${ }^{b}$ & 3 \\
\hline Wet particle deposition of $1,2,3,7,8-\mathrm{PeCDF}^{\mathrm{b}}$ & 2 \\
\hline Wet particle deposition of $1,2,3,4,7,8-\mathrm{HxCDF}^{\mathrm{b}}$ & 2 \\
\hline Plant surface loss coefficient ${ }^{b}$ & 1 \\
\hline $\begin{array}{l}\text { Wet deposition from vapor phase of } 1,2,3,7,8- \\
\text { PeCDF }\end{array}$ & 1 \\
\hline Soil enrichment ratio ${ }^{\mathrm{b}}$ & 1 \\
\hline Bioconcentration factor of $1,2,3,7,8-\mathrm{PeCDF}^{\mathrm{b}}$ & 1 \\
\hline
\end{tabular}

${ }^{\mathrm{a}}$ Parameters with variability.
${ }^{\mathrm{b}}$ Parameters with uncertainty.

aboveground vegetables, while the above five parameters collectively accounted for about $33 \%$ of the overall risk variance. Among the parameters with uncertainty, 10 parameters had contribution that was no less than $1 \%$, including fraction of chicken diet that is soil, USLE cover management factor, USLE length-slope factor, and interception fraction of aboveground vegetables, etc. The 10 parameters collectively accounted for about $21 \%$ of the overall risk variance, while the remaining 502 parameters accounted for about $44 \%$ of the overall risk

Table 3

Contribution of variation in concentrations of 12 environmental and exposure media to overall risk variance

\begin{tabular}{llllllllllll}
\hline $\begin{array}{l}\text { Media } \\
\text { concentration }\end{array}$ & Eggs & $\begin{array}{l}\text { Aboveground } \\
\text { vegetables }\end{array}$ & Poultry & Soil & Fruit & Dairy & Beef & Air & $\begin{array}{l}\text { Surface } \\
\text { water }\end{array}$ & $\begin{array}{l}\text { Root } \\
\text { vegetables }\end{array}$ & $\begin{array}{c}\text { Pork } \\
\text { Fish }\end{array}$ \\
\hline $\begin{array}{l}\text { Contribution to } \\
\text { variance (\%) }\end{array}$ & 44 & 19 & 18 & 13 & 4 & 1 & 1 & 0 & 0 & 0 & 0 \\
\hline
\end{tabular}

Table 4

Contribution of variation in risk estimates through 12 exposure pathways to overall risk variance

\begin{tabular}{|c|c|c|c|c|c|c|c|c|c|c|c|c|}
\hline $\begin{array}{l}\text { Exposure } \\
\text { pathways }\end{array}$ & $\begin{array}{l}\text { Ingestion } \\
\text { of above- } \\
\text { ground } \\
\text { vegetables }\end{array}$ & $\begin{array}{l}\text { Inges- } \\
\text { tion of } \\
\text { eggs }\end{array}$ & $\begin{array}{l}\text { Inges- } \\
\text { tion of } \\
\text { poultry }\end{array}$ & $\begin{array}{l}\text { Inges- } \\
\text { tion of } \\
\text { fruit }\end{array}$ & $\begin{array}{l}\text { Inges- } \\
\text { tion of } \\
\text { soil }\end{array}$ & $\begin{array}{l}\text { Inges- } \\
\text { tion of } \\
\text { fish }\end{array}$ & $\begin{array}{l}\text { Inges- } \\
\text { tion of } \\
\text { dairy }\end{array}$ & $\begin{array}{l}\text { Inhala- } \\
\text { tion }\end{array}$ & $\begin{array}{l}\text { Inges- } \\
\text { tion of } \\
\text { beef }\end{array}$ & $\begin{array}{l}\text { Inges- } \\
\text { tion of } \\
\text { drinking } \\
\text { water }\end{array}$ & $\begin{array}{l}\text { Inges- } \\
\text { tion of } \\
\text { root veg- } \\
\text { etables }\end{array}$ & $\begin{array}{l}\text { Inges- } \\
\text { tion of } \\
\text { pork }\end{array}$ \\
\hline $\begin{array}{l}\text { Contribu- } \\
\text { tion }(\%)\end{array}$ & 37 & 27 & 18 & 10 & 3 & 2 & 1 & 1 & 1 & 0 & 0 & 0 \\
\hline
\end{tabular}


variance. Information on the parameters should be collected according to priority based on contribution to variance of risk estimates.

Table 3 shows the contribution of variation in dioxin concentrations of 12 environmental and exposure media to overall risk variance. It was found that the contribution of the variation in dioxin concentrations for the 12 media to the overall risk variance ranged from $0 \%$ to $44 \%$. Variation in concentrations in eggs had the largest contribution of $44 \%$, while variation in concentrations in eggs, aboveground vegetables, poultry, soil, and fruit collectively accounted for about $98 \%$ of the total risk variance. Table 4 lists the contribution of variation in risk estimated through exposure pathways to overall risk variance. The contribution of the variation in risk estimated through 12 exposure pathways to the overall risk variance ranged from $0 \%$ to $37 \%$. Variation in the risk estimates through exposure pathways of aboveground vegetables, eggs, poultry, fruit, and soil ingestion accounted for about $95 \%$ of the overall risk variance. There were differences in the order of significance between variation in media concentrations (Table 3) and variation in the exposure pathways associated with the corresponding media (Table 4). These differences were due to the fact that variation in risk estimates is a combination of variation in media concentrations and variation in exposure parameters. Summarizing the findings of Tables 3 and 4, the study found that in order to obtain better estimation of cancer risk, high priority should be placed in resolving the uncertainty associated with the risk estimation through the five exposure pathways in addition to collecting sufficient samples on these five media to characterize and further reduce uncertainty associated with dioxin contents in these media.

Table 5 displays the risk values at the $50 \%, 75 \%$, and 95\% cumulative probability distribution levels, categorized by environmental medium and exposure medium. The total risk ranged from $5.2 \mathrm{E}-8$ at the 50 th percentile to $2.2 \mathrm{E}-7$ at the 95 th percentile, one order of magnitude lying between the two percentiles of the total risk distribution. The contribution of inhalation ranged from $3 \%$ of the total risk at the 95 th percentile to nearly $10 \%$ of the total risk at the 50th percentile while the contribution of ingestion was greater than $90 \%$ for all of the three percentiles. In terms of the importance of environmental media, it was found that soil and air were the major environmental media, whose contamination led to around $97 \%$ of the total risk. Regarding the comparison between exposure media, the order of significance was found to change between different percentiles. The five most important risk sources in terms of exposure medium in descending order were: ingestion of aboveground vegetables, ingestion of eggs, inhalation, ingestion of poultry, and ingestion of soil for the 50th percentile; ingestion of aboveground vegetables, ingestion of eggs, ingestion of poultry, ingestion of fruit, and

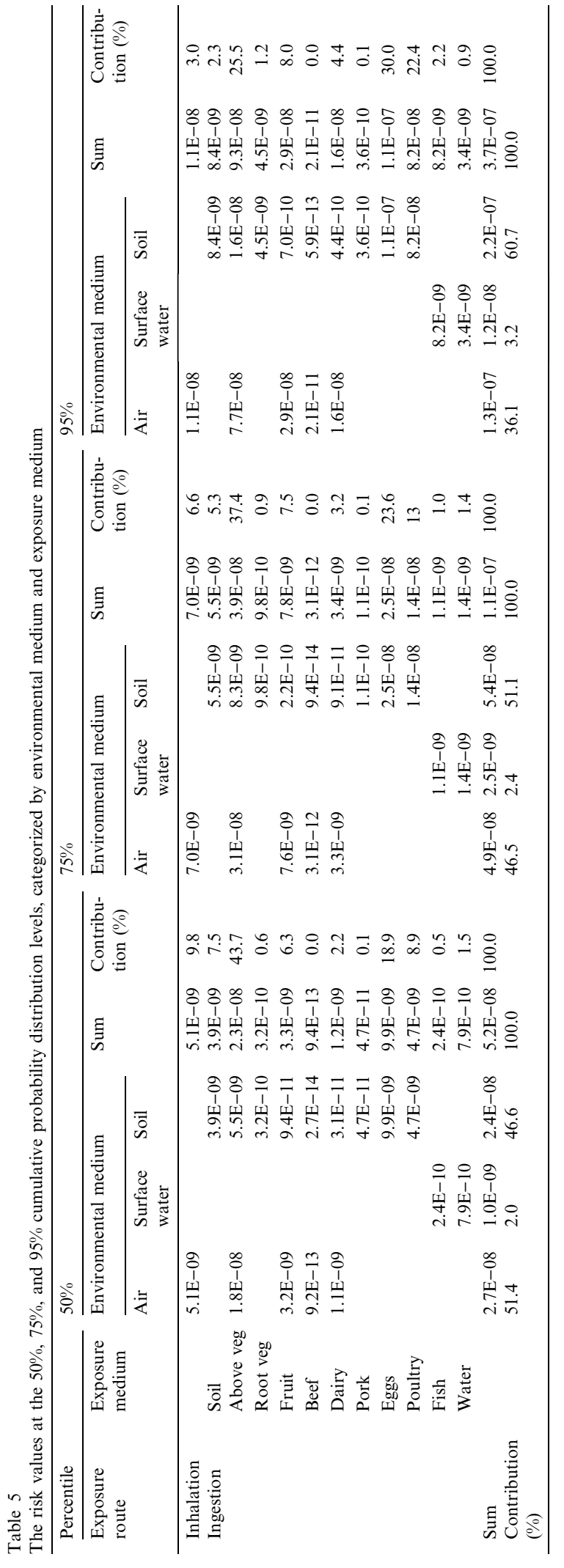


inhalation for the 75th percentile; ingestion of eggs, ingestion of aboveground vegetables, ingestion of poultry, ingestion of fruit, and ingestion of dairy produce for the 95th percentile. When the risk values at the 95th percentile are used for developing risk management measures, it is found that the cancer risk resulted primarily from ingestion of eggs (contributing about $30 \%$ of the total risk), ingestion of aboveground vegetables (contributing around $25 \%$ ), and ingestion of poultry (contributing about $22 \%$ ). The ingestion of the three exposure media accounted for about $77 \%$ of the total risk, so the priority of risk control efforts should be placed on these exposure pathways.

\section{Conclusion}

The study has combined site-specific multimedia risk assessment and the Monte Carlo method to perform a stochastic risk assessment for dioxin emissions from a municipal incinerator. The important sources of risk were found to be soil and air in terms of environmental medium, and eggs, aboveground vegetables, and poultry in terms of exposure medium for the $95 \%$ cumulative distribution level of the total risk distribution. The risk control measures focused on these media should receive priority. The study also combined the Monte Carlo method with calculations of rank correlation coefficients to prioritize the collection of information on parameters, dioxin contents of environmental and exposure media, and estimation of risk through exposure pathways. It was found that intake rates of aboveground vegetables, eggs, and poultry were the three most sensitive parameters that had the largest contribution to overall risk variance. Regarding the relative influence of the variation in concentrations in environmental and exposure media, the variation in concentrations in eggs, aboveground vegetables, poultry, soil, and fruit collectively accounted for more than $98 \%$ of the total risk variance. Regarding the relative influence of the variation in risk estimation through various exposure pathways, ingestion of aboveground vegetables, eggs, poultry, fruit, and soil was a significant source of risk variance. This study has demonstrated that a few parameters, environmental and exposure media, and exposure pathways were key factors that governed estimation of cancer risk of dioxin emissions, and that a few exposure pathways served as the primary contributors to risk.

\section{References}

Alcock, R.E., Gemmill, R., Jones, K.C., 1999. Improvements to the UK PCDD/PCDF and PCB atmospheric emission inventory following an emission measurement programme. Chemosphere 38, 759-770.

California EPA, 1993. CalTOX: A Multimedia Total Exposure Model for Hazardous-Waste Sites. Sacramento.

Covello, V.T., Merkhofer, M.W., 1993. Risk Assessment Methods: Approaches for Assessing Health and Environmental Risks. Plenum Press, New York.

Crawford-Brown, D.J., 1999. Risk-Based Environmental Decisions: Methods and Culture. Kluwer Academic Publishers, Norwell, MA.

Dempsey, C.R., Oppelt, E.T., 1993. Incineration of hazardous waste: a critical review update. Journal of Air and Waste Management Association 43, 25-73.

Gotoh, Y., Nakamura, Y., 1999. Japanese source inventory focusing on the emission reduction measures in the manufacturing industries sector. Organohalogen 41, 477-480.

Iman, R.L., Helton, J.C., 1988. An investigation of uncertainty and sensitivity analysis techniques for computer models. Risk Analysis 18, 71-90.

Lauretis, R.D., 1999. Dioxins and furans Italian national and local emission inventories. Organohalogen 41, 487-489.

Levin, A., Fratt, D.B., Leonard, A., Bruins, R., Fradkin, L., 1991. Comparative analysis of health risk assessments for municipal waste combustors. Journal of Air and Waste Management Association 41, 20-31.

Ma, H., 2000. The incorporation of stochasticity in risk analysis and management: a case study. Stochastic Environmental Research and Risk Assessment 14, 195-206.

McKone, T.E., 1991. Estimating human exposure through multiple pathways from air, water, and soil. Regulatory Toxicology and Pharmacology 13, 36-61.

Mills, W.B., Lew, C.S., Hung, C.Y., 1999. Sensitivity analysis of concentration and risk predictions in the PRESTO and MMSOIL multimedia models: regression technique assessment. Risk Analysis 19, 511-525.

NRC, 1994. Science and Judgment in Risk Assessment. Washington, DC.

Siebert, P.C., Alston, D.R., 1991. Toxic trace pollutants from incineration. Environmental Progress 10, 1-12.

Strenge, D.L., Chamberlain, P.J. 1995. The Multimedia Environmental Pollutant Assessment System (MEPAS): Exposure Pathway and Human Health Impact Assessment Models. Prepared for US DOE at Battelle.

USEPA, 1992. Integrated Risk Information System (IRIS). Office of Research and Development, Cincinnati.

USEPA, 1995. User's Guide for the Industrial Source Complex (ISC3) Dispersion Models: Volume I-User Instructions. Washington, DC.

USEPA, 1997. Guiding Principles for Monte Carlo Analysis. Office of Research and Development, Cincinnati.

USEPA, 1999. Human Health and Ecological Risk Assessment Support to the Development of Technical Standards for Emissions from Combustion Units Burning Hazardous Wastes: Background Document. Washington, DC.

Valberg, P.A., Drivas, P.J., McCarthy, S., Watson, A.Y., 1996. Evaluating the health impacts of incinerator emissions. Journal of Hazardous Materials 47, 205-227.

World Health Organization (WHO), 1999. Dioxins and their effects on human health. Fact sheet No. 225, June. Available from http://www.who.int/. 